\title{
Early-Life Contributors to Child Well-Being
}

\section{Nutrition' \& Metabolism}

\section{Feeding Practices and Parenting: A Pathway to Child Health and Family Happiness}

\author{
Lynne Allison Daniels \\ School Exercise and Nutrition Sciences, Faculty of Health, Queensland University of Technology, \\ Brisbane, QLD, Australia
}

\section{Key Messages}

- Feeding and parenting are inextricably linked. They shape the early feeding environment which interacts with genetics to influence the development of child eating patterns, which in turn are key determinants of life-long eating habits and associated health outcomes.

- Parents frequently misinterpret "normal" child eating behaviour as a cause for concern and respond with coercive, non-responsive feeding practices that are associated with adverse outcomes for child food preferences, appetite regulation and weight status. In addition, such practices may be a source of stress and distress for both parents and child.

- Parents respond positively to interventions designed to promote responsive feeding practices with positive outcomes for child eating behaviour and growth, stress and distress related to child feeding and broader parent-child interactions and family happiness and well-being.

\section{Keywords}

Child feeding behaviour - Parent feeding practices - Early feeding intervention - Responsive feeding practices . NOURISH RCT

\section{Abstract}

Feeding and parenting are inextricably linked. The complex bidirectional interactions between parent feeding practices and child eating behaviour shape the early feeding environment which in turn interacts with genetic predispositions to lay the foundation for life-long eating habits and health outcomes. Parent feeding and child (and parent) eating are central to the fabric of family life and are strongly rooted in culture and tradition. Yet, many parents experience stress and anxiety related to this ubiquitous parenting task and perceive their child as a "fussy eater" or a "difficult feeder." Parents commonly misinterpret heritable and developmentally "normal" child eating behaviour, such as food refusal, as cause for concern. In an effort to get their child to "eat well" they respond with coercive feeding practices, such as pressure, reward and restriction. Emotional feeding that uses food to comfort, distract, calm or shape behaviour is also common. Although well intentioned, these non-responsive,

\section{KARGER}

(c) 2019 S. Karger AG, Basel

E-Mail karger@karger.com

www.karger.com/anm
Lynne Allison Daniels

E-Mail L2.daniels@qut.edu.au 
parent- rather than child-centred feeding practices are ineffective, even counterproductive. They teach children to eat for reasons unrelated to appetite and, hence, more than they need and fail to support development of healthy food preferences and appetite regulation. Early feeding interventions are needed that assist parents to understand normal child eating behaviour and promote responsive feeding practices and effective food parenting. The aim of this chapter is to review (1) "normal" eating behaviour of young children, (2) the range of feeding practices and strategies that parents use to respond to and try to shape these behaviours, (3) evidence for approaches to feeding young children that have potential to reduce conflict related to child feeding and promote life-long healthy eating patterns that are a key determinant of long-term health and well-being and (4) to provide an overview of an early feeding intervention, NOURISH, which demonstrated a positive impact on maternal feeding practices and potentially reduced parent anxiety and stress related to feeding.

(c) 2019 S. Karger AG, Basel

\section{Introduction}

Feeding and parenting are inextricably linked, and infant feeding is central to the first maternal-child interactions [1]. Both feeding and parenting contribute to child physical, social, cognitive and behavioural development and well-being [2-4]. Consistent with the life course model [5], genetics and the early feeding environment interact to shape child food preferences, dietary intake and behaviours [6]. These lay the foundation for life-long eating habits and behaviours, which in turn are powerful predictors of long-term health outcomes, such as obesity, diabetes, cardiovascular disease and some cancers [7]. Parents are the gatekeepers of the early feeding environment which is shaped by complex parent-child interactions in the context of feeding and eating. These interactions have been termed "food parenting" [8]. In parallel with general parenting constructs, food parenting is considered to include feeding style and feeding practices. Feeding style is the broad emotional climate of the feeding dynamic, and feeding practices are the specific strategies and actions (the "when, what and how") of child feeding [8]. In this paper, "feeding" refers to what parents do to nourish their child. "Eating" is what the child does and includes food preferences, dietary (nutrients and food) intake and eating behaviour. Increasingly, evidence suggests that food parenting involves bidirectional interactions whereby parent feeding practices can influence and/or respond to child eating behaviours [9-11].
Parent feeding and child eating are central to the fabric of family life and are strongly rooted in culture and tradition. Yet, many parents experience stress and anxiety rated to this ubiquitous parenting task and perceive their young child as a "difficult feeder." Tensions and battles related to feeding young children are common and have the potential to impact on the quality of family meal times, parent confidence and broader family dynamics and well-being [12]. The aim of this chapter is to review (1) our understanding of "normal" eating behaviour of young children, (2) the range of feeding practices and strategies that parents use to respond to and try to shape these behaviours, (3) evidence for approaches to feeding young children that have potential to reduce conflict related to child feeding and promote life-long healthy eating patterns and (4) to provide an overview of an early feeding intervention, NOURISH, which demonstrated a positive impact on and improved maternal feeding practices.

\section{"Normal" Child Eating Behaviours and Appetite Traits}

Child eating behaviours are a product of complex interactions between genetics and environment $[13,14]$. Infants are born with predispositions that include a preference for sweet tastes and rejection of bitter/sour tastes and novel or unfamiliar foods. These genetic predispositions probably had evolutionary advantages whereby the child readily accepted sweet energy-dense foods (including breast milk) and avoided bitter (e.g., vegetables) and unfamiliar foods that were potentially toxic. These preferences are no longer adaptive in our current food environment where our food supply is largely safe, energy-dense foods are readily available and childhood obesity is prevalent [15-18]. Neophobia or rejection of novel foods is present from weaning and strengthens with child autonomy to peak at $2-5$ years of age $[17,18]$. These inborn heritable preferences can be modified by early feeding experiences, such as repeated neutral exposure to facilitate familiarity and acceptance [16-21]. It appears that food likes and dislikes are broadly established by $3-5$ years of age and persist over time $[18,21]$. Infants also have an inborn capacity to regulate their energy intake to need and operationalise this via cues of hunger and satiety. Parent recognition and responses to these cues are an integral component of food parenting and can either support or undermine this intrinsic self-regulation, which provides the foundation for healthy growth and longterm weight status $[3,4,22,23]$.
Daniels 
Table 1. CEBQ subscales validated for use in 2- to 8-year-old children [24]

\begin{tabular}{ll}
\hline Behaviour scale & No. of items; example \\
$\begin{array}{l}\text { Food approach behaviours } \\
\text { Food responsiveness }\end{array}$ & 5 items; "my child's always asking for food" \\
Emotional overeating & 4 items; "my child eats more when anxious" \\
$\begin{array}{l}\text { Desire to drink } \\
\text { Enjoyment of food }\end{array}$ & 3 items; "my child is always asking for a drink" \\
\hline Food avoidance behaviours & 4 items; "my child loves food" \\
Satiety responsiveness & \\
Emotional undereating & 5 items; "my child gets full up easily" \\
Slowness in eating & 4 items; "my child eats less when tired" \\
Food fussiness & 4 items; "my child eats more slowly during the course of a meal" \\
\hline
\end{tabular}

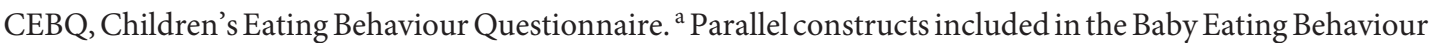
Questionnaire [25].

Eating behaviours in childhood ( $2-8$ years) are widely described and assessed using the parent-report Children's Eating Behaviour Questionnaire (CEBQ). The 8 behaviour/style scales (Table 1 ) have been broadly categorised into 4 food "approach" behaviours and 4 food "avoidance” behaviours [24]. The parallel Baby Eating Behaviour Questionnaire [25] has also been developed for use in infants. It includes 4 constructs in common with the CEBQ (Table 1), with items modified to account for milk feeding and an additional single item "my baby had a big appetite." More recently, it has become clear that these behaviours have a strong genetic component and are now often referred to as "appetitive traits" [26, 27]. Children rated highly on the "food approach" or "food avoidance" scales have been described as having a "big" or "small" appetite, respectively, and these clusters of traits have been prospectively associated with weight status $[13,28]$. Recent evidence indicates that, notwithstanding their heritability, these traits/behaviours are to some degree both responsive to and able to drive food parenting $[9,11$, 29, 30, 31].

Food fussiness (FF) or "picky eating" is an eating behaviour reported by $10-50 \%$ of parents and a source of considerable concern and conflict in families [18, 32-35]. There is no consensus on the definitions of "fussy" or "picky" eating [33]. This umbrella label is attributed to a cluster of child behaviours that centre on food refusal, where anecdotally the child does not eat what or as much as their carer thinks they should. Parents want their child to be a "good eater" and praise them for eating all that is offered [36]. FF is largely a matter of parent perception, which confounds interpretation of studies, as most assessment tools are based on parent self-report [36]. FF typically includes refusal of both familiar and unfamiliar foods [32-34]. Neophobia or refusal of unfamiliar foods is frequently labelled as FF but, as discussed above, is a normal developmental phase that may once have conferred evolutionary advantage $[16,18]$. It is also heritable but varies with age, and some adults retain neophobic eating behaviours [34, 37]. Parents often also report concern about erratic appetite and seemingly "ad hoc" refusal of foods which their child both is familiar with and usually eats [32,35]. Whilst often perceived as a "negative" eating behaviour, such refusal potentially signals satiety and the child's intrinsic self-regulation in action. It may also be a means by which a toddler can assert their emerging need for autonomy [2, 3, 23, 32]. Quality prospective studies examining the impact of FF on objectively measured dietary intake and growth are scarce [33]. Consistent with the notion that FF is primarily a matter of parent perception of developmentally "normal" eating behaviour, there is very little evidence of an adverse impact of FF on growth and development in healthy children born at term [36]. However, there is evidence that there are bidirectional prospective relationships between maternal-reported FF and undesirable maternal food practices $[11,30]$. Parent (fathers' and mothers') concern (how frequently they worried about 4 aspects of fussy eating) has been shown to fully mediate the cross-sectional relationships between FF and inappropriate parent feeding practices [38]. A recent study [36] reported that $30 \%$ of mothers perceived their child (age 14 months) as a "fussy eater." This perception was associated with mothers reporting that their child mostly decided how much to eat and with a lower relative weight (researcher measured), but not with objectively assessed dietary intake or quality. Importantly, 
all children were within the healthy weight range. The perception of their child as a fussy eater at 14 months, despite healthy weight status and no measurable relative reduction in dietary quality, was prospectively associated with less appropriate food parenting at 2 years of age [36]. In summary, it is the characterisation of developmentally normal food refusal in young children as "fussy eating" and a problematic non-compliant behaviour [35] that is more of an issue than the behaviour per se. Assisting parents to understand that these child eating behaviours commonly labelled as "fussy" or "picky" eating are influenced by genetics and developmental stage and, hence, are "normal" and, furthermore, could be important signals of satiety, may reduce anxiety and concern related to feeding and have a positive impact on food parenting.

Child eating behaviours manifest in the context of child characteristics, such as temperament, and broader developmental tasks, such as autonomy, separation, selfregulation and acquisition of motor skills [2]. From 12 to 24 months of age, growth and weight gain slow such that relative energy and hence food requirements/appetite decrease. In addition, neophobia escalates and separation/ autonomy becomes a key developmental task [34, 35]. Suddenly, parents are faced with a baby who was a "good eater" transitioning to a toddler who has an erratic appetite and overall appears to eat less, insists on self-feeding despite limited fine motor skills and feeding competence, starts to show distinct likes and dislikes and refuses foods previously well accepted, needs to assert and test their emerging independence, is much more mobile and less willing to sit still for extended periods and is often frustrated with the many tasks of emotional, cognitive and physical development [39]. Feeding provides numerous opportunities every day for the parent and child to interact around these issues and, if not managed well, has great potential to induce stress and distress for both. It is impossible to "make" children eat. Efforts to do so, even though they are well intentioned, are not only ineffective but can also be counterproductive in terms of developing healthy long-term eating patterns. Furthermore, they may undermine general parenting confidence and effectiveness [2, 39].

In summary, child eating behaviours are complex and include the expression of inborn food preferences and appetitive traits, neophobia, emotional responses to food and intrinsic regulation of intake via signals of hunger/ satiety. They are in part heritable and influenced by a range of other child characteristics, such as temperament (also heritable), developmental stage and possibly gender $[2,39]$. Parent understanding of and responses to these "normal" behaviours manifest in feeding styles and practices that in turn influence both short- and long-term eating behaviours and habits. It is increasingly clear that the parent-child feeding dynamic is bidirectional. Clearly, we cannot work directly with young children to influence their early eating behaviours. However, food parenting is modifiable [40-42]. Ensuring that parents have realistic expectations of the early feeding dynamic as well as the confidence and skills to respond appropriately to "normal" and changing child eating behaviour in the context of overall child development has great potential to reduce anxiety and conflict.

\section{Parent Feeding Practices and Their Potential Relationship with Parent-Child Conflicts}

Parents, particularly mothers, report considerable anxiety related to feeding, with a third to half of mothers reporting that their otherwise healthy child is difficult to feed or fussy $[32,33,41]$. There are a range of cultural, social and biological factors that contribute to the common notion that infants and particularly toddlers are "difficult to feed." From an evolutionary perspective, a reliable, plentiful food supply is a very recent phenomenon. It is plausible that mothers are "hardwired" to feed their children as often and as much as possible to ensure survival. Child feeding is strongly embedded in culture and tradition, and feeding practices are passed from grandmother to mother to daughter [15]. Even in highincome countries, it is only $2-3$ generations ago that feeding children occurred in the context of comparative food scarcity $[43,44]$. The traditional approaches to child feeding in this context are likely to be ineffective, even counterproductive, in our current environment where food is widely available and relatively affordable, unhealthy foods are ever present and heavily marketed, particularly to children, and excess consumption is the "norm." Furthermore, new approaches to child feeding are required that are adapted to shifts in economic and social factors (e.g., family structures, parent work patterns, eating out) [15].
Daniels 
From a sociological perspective, even in our contemporary societies, there are pervasive expectations that "good women" are "good mothers" and "good mothers" feed their children well. Adding to these pressures are well-intentioned but potentially misinformed and unhelpful advice from family and friends and an abundance of information of highly variable validity available on the internet. Despite good intentions, parents are likely to use traditional feeding practices advised and supported by family and friends without understanding the potential impact on child health in the context of the radically changed contemporary food supply $[2,15]$. The "obesity epidemic" further adds to parent pressure. There is heightened awareness of the adverse short- and long-

\section{Parents are likely to use traditional feeding practices advised and supported by family and friends without understanding the potential impact on child health in the context of the radically changed contemporary food supply}

term outcomes of overweight/obesity. With around 25\% of children and up to $70 \%$ of adults above the healthy weight range [45], this is a salient issue for many families. Up to three-quarters of women aged 25-45 years (and hence mothers), even those within the healthy weight range, report degrees of disordered eating or concern about their weight that interfere with their happiness [46]. Mothers plausibly wish to avoid passing their issues related to food and eating on to their children. There is evidence that maternal eating behaviours are associated with feeding practices [47] and child eating behaviour [48]. In addition, even in non-clinical samples, there is a relationship between child feeding and parental emotional and psychological well-being $[49,50]$. It is no wonder parents find the "what, when, where and how" of food parenting a source of concern and conflict.

There are numerous conceptualisations and tools used to describe and measure parent feeding practices [51-53]. Table 2 summarises a variety of prevalent feeding practices with practical examples. In a recent review, Vaughn et al. [8] sought to rationalise food parenting constructs and terminology. They identified 3 overarching food parenting constructs: coercive control; structure; autonomy support of promotion. "Coercive control" includes pressure and authoritarian, overt restriction, both of which

Feeding Practices and Parenting override the child's hunger and satiety cues and undermine their capacity to self-regulate intake and hence are classified as non-responsive feeding practices [3, 4, 23]. Emotional or instrumental feeding practices (e.g., using food to calm; see Table 2) are also categorised as nonresponsive [53]. These parent-centred, controlling feeding practices are prevalent and postulated to teach children to eat for reasons unrelated to appetite and to habitually eat more than they want or need $[3,4,23,32]$. There is a substantial body of evidence which indicates that such non-responsive feeding practices are associated with poor outcomes in terms of child eating behaviour, diet quality and weight status $[3,4,8,15,23,31,54,55]$. Consequently, interventions have generally sought to have parents avoid/reduce these behaviours. This "deficit" approach requires parents to "stop doing things" and has potential to contribute to parent guilt and anxiety.

"Structure" refers to practices that parents can use to organise and manage the eating environment such that child feeding competence and autonomy, enhanced food acceptance and intrinsic regulation of intake are encouraged. Examples are shown in Table 2 and include rules, limits and routines related to eating $[8,52,56]$. Hurley et al. [23] argue that structure provides a context in which the child can clearly express their hunger/satiety cues and parents are more able to appropriately recognise, interpret and respond to these cues. Structure practices, such as family meal times and routines, also provide important opportunities for socialisation to family food practices and traditions [8]. A recent study [56] demonstrated that structure operationalised via meal setting (where the child eats) and family meal setting (eats the same food as the family) were associated with parents reporting increased child ability to regulate food intake, based on an 8 -item scale. Mealtime structure has also been associated with improved child FF, enjoyment of food and child and family well-being $[56,57]$. Encouraging structure and limits related to eating offers a strengths-based approach to promoting positive feeding practices. Furthermore, the strategies are comparatively straightforward to understand and implement [56].

"Autonomy support" explicitly links food parenting practices to age-appropriate developmental milestones, such as emotional self-regulation, independence and cognitive capability [8]. It includes strategies that aim to develop food literacy (education, reasoning, involvement in preparation) and positively support (encourage, negotiate, praise) development of healthy eating habits. Promoting "autonomy support" strategies is also potentially a strength-based approach but requires explicit promo- 
Table 2. Prevalent parent feeding practices that are associated with poor outcomes for child dietary quality, eating patterns, behaviour and weight status $[3,4,8,9,15,16,23,32,37,53,54,56]$

\begin{tabular}{ll}
\hline Feeding practices and outcomes & Examples \\
\hline $\begin{array}{l}\text { Coercive, non-responsive, authoritarian, parent-centred } \\
\text { Pressure }\end{array}$ & Focus on portions size, decide how much child should eat \\
Active encouragement to eat more & Game playing \\
Overrides child satiety cues - usually & Encourage "one more mouthful" \\
expressed as food refusal & Praise for eating all that is given \\
$\rightarrow$ Undermines capacity to self-regulate & Offer food reward for eating, e.g., dessert if eat vegetables \\
intake & Offer non-food reward for eating, e.g., watch TV if eat \\
& vegetables \\
& Threaten if child does not eat, e.g., withhold dessert or TV \\
& Offer alternative liked food or drink - "as long as they eat \\
& something" \\
& Insist that child eats, override self-feeding attempts \\
\hline
\end{tabular}

Restriction

Overtly limit access to unhealthy foods child recognises restriction

Limited reasoning, choice

$\rightarrow$ Increases desirability of restricted food
Withhold dessert if child does not eat rest of the meal Do not allow child to have unhealthy foods even though they are overtly available to adults in the household Allow no access to "treat" foods Restrict on basis of "good" versus "bad" foods

\section{Emotional feeding}

Use food in response to negative emotions comfort, calm, distract; shape behaviour

$\rightarrow$ Teaches child to eat for reasons unrelated to appetite

Offer food in return for good behaviour Withhold food to punish bad behaviour Offer food to keep child quiet Offer food when child is upset or hurt Person praise ("good girl") for desired eating behaviour

\section{Unstructured permissive/indulgent feeding}

Eating environment disorganised

Few limits to what, where and when of eating occasions

$\rightarrow$ Fails to facilitate clear expression of appetite cues by child and recognition by parents

$\rightarrow$ Fails to facilitate feeding competence, support autonomy

\section{Response to neophobia - rejection of unfamiliar foods}

Exposure to limited range of tastes and textures

Only offer preferred, liked foods

$\rightarrow$ Fails to maximise opportunities to become familiar with and learn to like and accept new foods
Child given whatever food they ask for, whenever they ask Variable and inconsistent meal frequency and location Young child is not included in family meals

Child eats different food to the rest of the family, only liked foods are offered at mealtimes

No limits on range of foods from which child can choose - includes unhealthy options Child allowed to eat wandering around

Distractions when eating, e.g., TV, access to toys
When new food is rejected, assume that child does not like it and do not reoffer Offer new food $<6$ times before deciding that child does not like

Disguise new foods

Insist/pressure on child to eat

Offer liked food instead

Reward for eating (rather than tasting)

Force feeding 
tion of a nuanced emotional tone associated with implementation to ensure practices do not become coercive, e.g., encouragement versus pressure and "process" praise (e.g., "well done for trying new food") versus "person" praise (e.g., "good girl for finishing your dinner") as an emotional reward [8].

Recommendations that seek to promote child-centred responsive feeding that recognises and responds appropriately to child cues of hunger and satiety and, hence, supports rather than undermines the child's inborn capacity to regulate intake are commonly based on the "trust" model [22]. This framework has also been termed the "Division of Responsibility" [39] ("parent provide, child decide") and argues that parents are responsible for providing safe, developmentally appropriate, nutritious food, while the child is responsible for deciding whether and how much they eat. As such, this approach discourages coercive and controlling feeding practices (pressure, restriction, reward) and emphasises the feeding dynamic. It has also been described as authoritative feeding, analogous to an authoritative parenting style, where the carer responds warmly, consistently and predictably to child cues but also sets limits via structure [4]. Both authoritative feeding and parenting have been associated with a broad range of positive developmental outcomes $[3,4]$.

The food parenting practices discussed thus far have largely focussed on the "how" of feeding in the context of supporting the child's intrinsic regulation of food (energy) intake. Food preferences are an important factor in food acceptance and choice ("what"), which in turn are key determinants of eating habits $[17,18]$. As indicated above, infants are born predisposed to prefer sweet tastes and reject bitter/sour and unfamiliar foods (neophobia). Whilst these traits are heritable, they are also modified by early feeding experience. Table 2 gives some examples of common feeding practices used in response to neophobia. There is considerable evidence that repeated neutral (i.e., non-coercive) exposure to a wide variety of foods, particularly whilst neophobia is relatively low (4-10 months) $[16,37]$, can ameliorate these innate preferences and promote new food acceptance and improved dietary variety [19] and dietary quality [16-18]. Cooke argues that young children need repeated neutral exposure to become familiar with foods so that they can "learn to like and then like to eat" [17]. In our current food environment, there are plenty of opportunities for infants/toddlers to experience and learn to like unhealthy (high-sugar/fat, low-nutrient) foods. Indeed, early exposure to unhealthy foods is associated with enhanced preference and potentially increased intake of these foods [20,21]. A recent prospective study [20] showed that the more variety of fruits and vegetables and the fewer non-core (high-fat/sugar, low-nutrient) foods a child had "tried" by 14 months of age predicted the number of foods within these food groups both liked and eaten, as well as improved diet quality at 3.7 years of age. Furthermore, children who had tried more vegetables by 14 months were also reported as less fussy at 3.7 years. These prospective associations were independent of maternal age, education, body mass index, duration of breast feeding, age of solid introduction and child

fussiness at 14 months. Overall, repeated neutral exposure to healthy foods and limiting exposure to unhealthy foods are important food parenting practices to support the development of healthy food preferences and eating habits. It is critical that parents are supported to implement these strategies in conjunction with responsive feeding practices and structure to avoid counterproductive coercive controlling feeding practices.

In summary, effective food parenting practices have the capacity to positively influence the development of early taste preference, texture tolerance and appetite regulation that lay the foundation for life-long healthy food preferences and eating behaviours. However, studies suggest that sub-optimal feeding practices, including coercive, non-responsive feeding, that are characterised by excess maternal control and that teach children to eat for reasons unrelated to appetite are prevalent. Studies show that dietary quality is poor even in very young children and suggest that feeding practices related to early exposure are also sub-optimal $[31,32,58]$. Evidence and clinical experience suggest that food parenting is a source of considerable anxiety and conflict within families and that once an adverse feeding dynamic is established, it is very difficult to change. Interventions that promote positive feeding practices and increase the skills and confidence to support effective food parenting have the potential to positively influence health and well-being at the parent, child and family levels. Yet, there are very few food parenting interventions that have been well-described and evaluated in large robust clinical trials. One such trial will be discussed in the following section. 
Table 3. NOURISH intervention strategies, principles and parent messages, adapted from Daniels [66 ${ }^{\mathrm{a}}$

\begin{tabular}{|c|c|c|}
\hline Evidence-based strategies & Intervention principles ${ }^{\mathrm{b}}$ & Parent concepts and strategies ${ }^{b}$ \\
\hline $\begin{array}{l}\text { Exposure: promoting repeated } \\
\text { neutral exposure to healthy foods; } \\
\text { limiting exposure to unhealthy } \\
\text { energy-dense nutrient-poor foods to } \\
\text { support development of healthy } \\
\text { food preferences [17] }\end{array}$ & $\begin{array}{l}\text { The way we feed young } \\
\text { children affects the food they } \\
\text { will like and their health } \\
\text { Habits are formed early and } \\
\text { track to adulthood } \\
\text { "Learning to like, liking to eat" } \\
\text { [17] }\end{array}$ & $\begin{array}{l}\text { Understand, expect neophobia, inborn taste } \\
\text { preferences - salt and sweet } \\
\text { Repeated neutral exposure: reoffer new healthy } \\
\text { foods up to } 10-15 \text { times to develop familiarity and } \\
\text { acceptance } \\
\text { Limit exposure to sweet, salty foods - covert } \\
\text { restriction, role modelling } \\
\text { Same food presented a different way is a new food } \\
\text { Tasting is important and spitting out is acceptable }\end{array}$ \\
\hline $\begin{array}{l}\text { Responsive feeding: recognising and } \\
\text { responding appropriately to child } \\
\text { cues of hunger and satiety to } \\
\text { support and maintain the child's } \\
\text { innate capacity to self-regulate } \\
\text { energy intake and avoid overfeeding } \\
{[3,4,22]}\end{array}$ & $\begin{array}{l}\text { Listen to and trust your child } \\
\text { "Parent provide, child decide" } \\
\text { [39] }\end{array}$ & $\begin{array}{l}\text { Accept food refusal = not hungry or satiety } \\
\text { Guide portion size but don't focus on amounts } \\
\text { Encourage autonomy - allow self-feeding to } \\
\text { developmental stage; accept mess } \\
\text { Neutral response to intake and refusal } \\
\text { - No coercion, coaxing, games } \\
\text { - No rewards, bribes, alternatives } \\
\text { - Praise for tasting, self-feeding efforts - not } \\
\text { for eating } \\
\text { No emotional feeding to distract, comfort, shape } \\
\text { behaviour } \\
\text { No TV }\end{array}$ \\
\hline $\begin{array}{l}\text { Positive parenting (warmth, encourage } \\
\text { autonomy, self-efficacy): } \\
\text { operationalised via authoritative } \\
\text { feeding characterised by behavioural } \\
\text { limits (structure) and maternal } \\
\text { sensitivity to cues; decreased over- } \\
\text { control and protection }[4,61,67]\end{array}$ & $\begin{array}{l}\text { Your relationship with your } \\
\text { child is important } \\
\text { "Feeding is parenting" } \\
\text { Set good examples for your } \\
\text { child } \\
\text { "Be a good role model" }\end{array}$ & $\begin{array}{l}\text { Set limits and rules } \\
\text { Allow structured choice - choose from limited } \\
\text { range of healthy foods based on what the family eats } \\
\text { Establish meal/snack times and routines that ensure } \\
\text { the child is hungry but not too hungry } \\
\text { Make mealtimes pleasant for the whole family; some } \\
\text { rules are important but don't over-focus on } \\
\text { manners } \\
\text { Warmth, independence - responsive to child cues } \\
\text { and skills } \\
\text { - Avoid overpowering (authoritarian), e.g., pressure } \\
\text { to clean plate } \\
\text { - Avoid over-worrying (permissive or } \\
\text { authoritarian), e.g., pressure to eat, overt restriction } \\
\text { - Avoid being a "big softie" (permissive or } \\
\text { unengaged) - "as long as they eat something"; } \\
\text { don't offer alternatives or be a "short-order cook" } \\
\text { Feeding is a conversation } \\
\text { - Allow the child to lead, wait until paying attention; } \\
\text { pause for socialising } \\
\text { - Allow self-feeding and touching food } \\
\text { - Avoid intrusions/disruptions, e.g., cleaning face } \\
\text { - Stop feeding when child loses interest } \\
\text { - Talk quietly - about the food, encourage but don't } \\
\text { coerce, teach language for hunger and fullness }\end{array}$ \\
\hline
\end{tabular}

a Adapted and reprinted with permission from Nestec Ltd., Vevey and S. Karger AG, Basel. ${ }^{\mathrm{b}}$ As articulated to parents.

\section{The NOURISH Intervention and Randomised Controlled Trial}

The NOURISH intervention was designed for firsttime mothers with healthy term infants. The aim was to promote "protective" feeding practices that supported the development of healthy child eating behaviours, food intake and growth. The focus was on feeding practices from the start of solid feeding onwards. The intervention was evaluated by a randomised controlled trial designed and implemented according to standard recommendations. The protocol, intervention content and process and outcomes have been reported in detail $[40-42,59]$. Briefly, first-time mothers of healthy term infants were initially approached on post-natal wards. Subsequently, 698 
mothers and infants (mean 4.3 months old) underwent baseline assessment and randomization. The intervention consisted of 2 modules of 6 group sessions of $1.5 \mathrm{~h}$ duration delivered fortnightly over 12 weeks. Sessions were facilitated at local child health clinics by study dietitians and psychologists using standardised facilitator and participant materials. The first module commenced immediately after baseline assessment at infants' age 4 months. The second module commenced 6 months after completion of the first ( 9 months from baseline) when the children were 14 months old. An important aspect of the NOURISH intervention was the use of an anticipatory guidance framework to provide parents with developmentally appropriate information about "normal" infant behaviours and constructive responses, rather than waiting to seek advice on established problems. This dictated commencing the intervention when the infants were about 4 months old, just as mothers started complementary feeding, consistent with the evidence that suggests that the very early feeding experience (food parenting) lays the foundation for life-long eating patterns $[15,60]$.

The NOURISH intervention strategies, themes and corresponding parent messages are shown in Table 3, and a summary of module content is shown in Table 4 . There were 3 content-targeted key domains of food parenting associated with positive outcomes in child eating behaviour, dietary quality and growth: (1) repeated neutral exposure to unfamiliar healthy foods and neutral limited exposure to unhealthy foods to promote healthy food preferences and acceptance of a wide range of tastes and textures [16, 17, 34]; (2) responsive feeding that attends to and responds appropriately to infant appetite cues to maintain and support self-regulation of intake to need and avoid overfeeding $[3,22,23]$ and (3) positive parenting - warmth, encouragement of autonomy and self-efficacy $[1,4,61]$. Modules were designed to be consistent with developmental stage. Module 1 focussed on complementary feeding, whilst module 2 concentrated on managing toddler eating behaviour, particularly in the context of developmental needs for autonomy, and promoting feeding competence. The control group had self-directed access to standard child health services which at the mothers' initiative could include a telephone helpline and child weight measurement.

Outcomes were assessed 6 months and 2 and 3.5 years after completion of the intervention/module 2 and cor- responding to child ages $2,3.5$ and 5 years, respectively $[31,41,42,55]$. Validated maternal-report tools were used to assess child intake (24-h recall), food preferences and eating behaviours and maternal feeding practices, strategies to manage food refusal and parenting skills. Longitudinal analysis evaluated differences between the intervention and control groups at the 3 time points over the 3.5-year follow-up period [41, 42]. Mothers allocated to the intervention group demonstrated sustained and statistically significant improvements in feeding practices relative to those in the control group up to 3.5 years after intervention completion. Intervention mothers reported using less non-responsive feeding on $6 / 9$ subscales [41, 42]. From 2 to 5 years of age, children in the intervention group were reported to have a small increase in satiety responsiveness and reduction in food responsiveness and fussiness, an overall pattern of appetite traits associated with healthier weight status [31]. The effect sizes were small, consistent with the heritability of these appetite traits as discussed above [26, 27], but provide evidence that increased use of responsive feeding practices may contribute to a reduction in "obesogenic" appetite traits consistent with healthy child eating behaviour [31]. These positive intervention effects on food parenting and child eating behaviour were associated with the body mass index $Z$-score at each follow-up assessment, being $16-17 \%$ lower $(p=0.06)$ for the intervention versus the control children. However, these positive intervention effects did not translate into measurable effects on food preferences or dietary intake or quality. There was no group effect on dietary intake assessed by a single 24 -h recall. There were small positive intervention effects on food preferences ( 75 vs. $69 \%$ liked 16 fruits listed) and fruit and vegetable variety and frequency over $24 \mathrm{~h}$ and 7 days [31].

The NOURISH trial did not explicitly examine outcomes related to maternal happiness or parent conflict or distress related to feeding. However, there were a number of significant and relatively large differences at each of the follow-up assessments in the ways mothers managed food refusal (see Table 5) that support speculation that the intervention was potentially effective in reducing maternal anxiety related to food parenting. Intervention mothers were 1.7 times more likely to allow their child to take responsibility for how much to eat and less likely to be concerned about their child's weight status [41]. Although at 2 years of age there were no group differences 
Table 4. NOURISH intervention content $[66]^{\mathrm{a}}$

\begin{tabular}{|c|c|c|}
\hline \multicolumn{2}{|c|}{$\begin{array}{l}\text { Module } 1 \\
\text { Session }\end{array}$} & \multirow{2}{*}{$\begin{array}{l}\text { Introducing solids: commenced child age } 4-7 \text { months } \\
\text { Exposure: "Learning to like, liking to eat" [17] } \\
\text { Food preferences - innate likes and dislikes, neophobia } \\
\text { Feeding practices - neutral exposure to a wide variety of healthy foods, limit } \\
\text { exposure to unhealthy foods } \\
\text { Parenting styles and feeding practices } \\
\text { Hunger and fullness cues }\end{array}$} \\
\hline 1. & Program introduction & \\
\hline 2. & $\begin{array}{l}\text { Parenting styles and feeding } \\
\text { practices }\end{array}$ & $\begin{array}{l}\text { Parenting styles and attachment, relationship to feeding } \\
\text { Feeding practices to support "attached" feeding }\end{array}$ \\
\hline 3. & $\begin{array}{l}\text { Healthy growth and feeding } \\
\text { babies }\end{array}$ & $\begin{array}{l}\text { Guide to healthy weight gain } \\
\text { Developmental readiness for solids } \\
\text { Process for introducing solids } \\
\text { Foods to avoid and how much }\end{array}$ \\
\hline 4. & The feeding relationship & $\begin{array}{l}\text { "Normal" infant feeding behaviour - variable intake, prefer sweet and salt (limit } \\
\text { these), support to try new things and learn to like new tastes } \\
\text { The feeding relationship - conversation, let the child lead }\end{array}$ \\
\hline 5. & $\begin{array}{l}\text { Healthy and safe feeding } \\
\text { skills }\end{array}$ & $\begin{array}{l}\text { "Listen" to your child, recognise and respond to hunger/satiety cues, offer new } \\
\text { foods, limit unhealthy foods } \\
\text { Rewards of attached feeding - increases child's confidence and emotional grounding } \\
\text { Safe food, EBM and formula handling and preparation }\end{array}$ \\
\hline 6. & Planning for the future & $\begin{array}{l}\text { Food refusal is "normal" - signals satiety - tips to manage; develop language to talk } \\
\text { about hunger, fullness } \\
\text { Introduction to "division responsibility" [39] } \\
\text { Setting limits and allowing choice within limits }\end{array}$ \\
\hline & & $\begin{array}{l}\text { Transition to family food, self-feeding: commenced child age 13-16 months } \\
\text { Division responsibility: "Parent provide, child decide" [39] }\end{array}$ \\
\hline 1. & Introduction & $\begin{array}{l}\text { Toddlers are different to babies - they want to be independent, increased neophobia } \\
\text { Toddlers don't grow as quickly as babies } \\
\text { Small and highly variable appetites - trust your child to know how much they need } \\
\text { to eat }\end{array}$ \\
\hline 2. & Healthy eating & $\begin{array}{l}\text { Food groups - number and serve sizes, sample menus, don't focus on amounts } \\
\text { Limit "extra" foods, avoid choking risks } \\
\text { Mealtime structure and strategies } \\
\text { No TV }\end{array}$ \\
\hline 3. & $\begin{array}{l}\text { Parenting styles and feeding } \\
\text { practices }\end{array}$ & $\begin{array}{l}\text { Warmth - praise for trying new foods, not for eating } \\
\text { Independence - let the child decide how much to eat, self-feeding } \\
\text { Over-powering - force feeding, over-worrying - clean the plate } \\
\text { "Big softie" - as long as they eat something }\end{array}$ \\
\hline 4. & $\begin{array}{l}\text { Feeding toddlers, } \\
\text { understanding autonomy }\end{array}$ & $\begin{array}{l}\text { Adult meals/foods, plan snacks } \\
\text { Provide choice within limits - parent decides "what and when" } \\
\text { Treat dessert as part of a meal, manage treats - "sometimes foods" - when, how } \\
\text { often and portion sizes } \\
\text { Self-feeding and feeding competence }\end{array}$ \\
\hline 5. & $\begin{array}{l}\text { Managing food refusal and } \\
\text { fads }\end{array}$ & $\begin{array}{l}\text { Food refusal is normal - satiety, autonomy } \\
\text { Regular meals/snacks } \\
\text { Realistic amounts, don't offer preferred alternative, especially milk } \\
\text { Avoid coercive feeding and excess control } \\
\text { Don't use food to shape behaviour; avoid emotional feeding (calm, distract, comfort) }\end{array}$ \\
\hline 6. & $\begin{array}{l}\text { Overview, planning for the } \\
\text { future }\end{array}$ & $\begin{array}{l}\text { Division responsibility, authoritative feeding and parenting } \\
\text { Food away from home, food at child care }\end{array}$ \\
\hline
\end{tabular}

EBM, expressed breast milk. ${ }^{a}$ Adapted and reprinted with permission from Nestec Ltd., Vevey and S. Karger AG, Basel. ${ }^{\mathrm{b}}$ Modules comprised fortnightly interactive group sessions ( $n=10-15 /$ group, duration $1.5 \mathrm{~h}$ ). Modules 1 and 2 commenced when children were approximately 4 and 14 months of age, respectively. 
Table 5. NOURISH intervention effects on maternal response to child food refusal [41, 42]

\begin{tabular}{|c|c|c|c|c|}
\hline \multirow[t]{2}{*}{ Response } & \multicolumn{2}{|c|}{2 years old $(n=467)$} & \multicolumn{2}{|c|}{5 years old $(n=392)$} \\
\hline & control & intervention & control & intervention \\
\hline \multicolumn{5}{|l|}{ Refusal of familial foods } \\
\hline \multicolumn{5}{|l|}{ Non-responsive/coercive: overrides satiety cues $^{\mathrm{a}}$} \\
\hline Insist child eats & 37 & 18 & 65 & 48 \\
\hline Offer milk drink instead & 22 & 14 & 6 & $3^{\text {ns }}$ \\
\hline Offer liked food instead & 78 & 63 & 41 & $37^{\text {ns }}$ \\
\hline \multicolumn{5}{|l|}{ Encourage/pressure to eat by } \\
\hline Playing games & 57 & 21 & not asked & \\
\hline Offering food reward for eating & 31 & 9 & 63 & 42 \\
\hline Offering non-food reward for eating & 27 & 18 & 39 & 29 \\
\hline Feeding with spoon & not asked & & 53 & 42 \\
\hline \multicolumn{5}{|l|}{ Responsive: respond appropriately to satiety cues ${ }^{\mathrm{a}}$} \\
\hline Accept that child is not hungry, take food away & 91 & 96 & 79 & 88 \\
\hline Offer no food until next usual meal/snack time & 48 & 67 & 64 & 77 \\
\hline Mother mostly responsible for what child eats & 76 & $72^{\text {ns }}$ & & \\
\hline Child mostly responsible for how much to eat & 49 & 82 & & \\
\hline \multicolumn{5}{|l|}{ Neophobia: refusal of unfamiliar foodsa } \\
\hline Assume child does not like and do not reoffer & 13 & 5 & 14 & $13^{\text {ns }}$ \\
\hline Neutral offer $\geq 6$ times before deciding child dislikes & 35 & 72 & 45 & 61 \\
\hline Disguise the food & 65 & 45 & 53 & 41 \\
\hline Offer with liked food & 94 & $94^{\mathrm{ns}}$ & 92 & $93^{\mathrm{ns}}$ \\
\hline
\end{tabular}

Frequency (\%) of strategies (explicitly addressed in intervention content) used. ns, not significant. ${ }^{a}$ Response options: $1=$ never to $5=$ most of the time OR $1=$ never to $4=$ often dichotomised to 1,2 versus $3,4,5$ and 1,2 versus 3,4 , respectively.

in the proportion of children reported to often/very often refuse food (22\%), intervention mothers were significantly more likely to report that their child was "easy to feed" and to report less FF. In response to food refusal, they were much less likely to insist that the child eats, offer alternate liked foods, use rewards, disguise foods or play games and more likely to accept that the child was not hungry, simply take the food away and offer no more food until the next usual snack/mealtime [31, 42, 55] (Table 5). The results consistently suggest that intervention mothers were more likely to use the "trust" [22] model and avoid using a range of coercive feeding practices that arguably contribute to conflict in the feeding dynamic. Process evaluation indicated that the intervention was well accepted, with $98 \%$ of participants indicating they would recommend NOURISH, and 99\% found the information to be very useful/useful. $85 \%$ of participants reported that the intervention helped them "a lot" to feel more confident about child feeding, and 95\% reported that it helped them to trust their child eats enough [62].

Overall, these results show that mothers (first-time at least) welcome and respond to anticipatory guidance on food parenting and that such guidance not only enhances maternal confidence but is able to modify maternal feeding practices with positive child outcomes. It is plausible that the intervention was associated with reduced anxiety and conflict and enhanced maternal confidence and wellbeing.

\section{Further Considerations}

With changes to the gender-based divisions of responsibilities for employment and parenting within families and society at large, fathers have an increasingly important role in early feeding. However, to date research into parental feeding practices has largely focussed on mothers [63]. Our unpublished data comparing feeding practices (using the Child Feeding Questionnaire [51]) in 70 parent pairs indicated that, compared to mothers, although fathers feel less responsible for child feeding, they are more concerned about child weight status and appear to more frequently use relatively controlling and, hence, suboptimal feeding practices. Other studies suggest that fathers of pre-schoolers more often used "insistence on 
eating" and food to reward good behaviour, while mothers more often used "positive persuasion" to eat and a range of strategies to enhance dietary quality (e.g., "snack limits") $[64,65]$. This discordance in food parenting has potential to contribute to parental conflict and stress. Whilst the importance of fathers in child feeding must not be forgotten, it is critical that interventions do not exacerbate conflict related to feeding and are explicitly designed to support parents to work together to achieve positive intervention outcomes. Cultural and ethnic background and a range of socio-demographic factors are likely to influence the roles of mothers and fathers in child rearing and feeding, and ensuring diversity in parents participating in interventions will be critical to building a robust evidence base for the role of early feeding practices of both parents.

\section{Conclusion}

Parent-child interactions related to feeding are central to the fabric of daily family life and contribute to all aspects of child development, health and well-being. Child eating behaviours are in part heritable, are influenced by a range of child characteristics and reflect normal developmental stages. They are both responsive to and drive parent feeding style and practices. Parents frequently misinterpret developmentally normal child eating behaviours, such as food refusal, as cause for concern and anxiety and respond with coercive feeding practices (pressure, restriction, emotional feeding). Clinical experience indicates that parents, in an attempt to just get a few more mouthfuls of food into their toddler, can resort to quite bizarre feeding practices that are a source of stress and distress for both parent and child. These parent-centred authoritarian practices may be well intentioned but are both counterproductive and associated with poor out- comes for child health, including development of food preferences and appetite regulation, which lay the foundation for life-long healthy eating habits and chronic disease risk. Furthermore, it is plausible that stress and conflict around feeding may generalise to the broader parentchild interactions and family dynamic and impact on family happiness.

Overall, there is evidence that food parenting can be improved with a potential to positively influence child eating behaviour, diet quality and weight status and, in the longer term, reduce chronic disease risk. It is important that interventions take a strengths-based approach and explicitly support parents to cooperate rather than exacerbate any discordance in feeding practices. Furthermore, given the central role that feeding and eating play in the parent-child interactions (particularly in young children), and indeed within the broader family and cultural contexts, it could be argued that effective food parenting contributes to healthy and happy children and families.

\section{Acknowledgements}

We acknowledge the NOURISH investigators, staff, students and participants. NOURISH was funded from 2008 to 2014 by 2 consecutive grants from the Australian National Health Medical Research Council. Additional funding was provided by H.J. Heinz, Meat \& Livestock Australia, Department of Health South Australia, Food Standards Australia New Zealand and Queensland University of Technology. We thank Dr Rebecca Perry for her contribution to the development of the NOURISH intervention content and materials.

\section{Disclosure Statement}

The writing of this article was supported by Nestlé Nutrition Institute and the author declares no other conflicts of interest.

\section{References}

1 Jansen E, Daniels L, Nicholson J. The dynamics of parenting and early feeding - constructs and controversies: a viewpoint. Early Child Dev Care. 2012;182(8):967-81.

2 Satter E. The feeding relationship: problems and interventions. J Pediatr. 1990 Aug;117(2 Pt 2):S181-9.

3 DiSantis KI, Hodges EA, Johnson SL, Fisher JO. The role of responsive feeding in overweight during infancy and toddlerhood: a systematic review. Int J Obes. 2011 Apr;35(4): 480-92.
4 Black MM, Aboud FE. Responsive feeding is embedded in a theoretical framework of responsive parenting. J Nutr. 2011 Mar;141(3): 490-4.

5 Pérez-Escamilla R, Kac G. Childhood obesity prevention: a life-course framework. Int J Obes Suppl. 2013 Jun;3(S1 Suppl 1):S3-5.

6 Lillycrop KA, Burdge GC. Epigenetic changes in early life and future risk of obesity. Int J Obes. 2011 Jan;35(1):72-83.
7 Leunissen RW, Kerkhof GF, Stijnen T, Hokken-Koelega A. Timing and tempo of firstyear rapid growth in relation to cardiovascular and metabolic risk profile in early adulthood. JAMA. 2009 Jun;301(21):2234-42.

8 Vaughn AE, Ward DS, Fisher JO, Faith MS Hughes SO, Kremers SP, et al. Fundamental constructs in food parenting practices: a content map to guide future research. Nutr Rev. 2016 Feb;74(2):98-117.
40

Ann Nutr Metab 2019;74(suppl 2):29-42 DOI: $10.1159 / 000499145$
Daniels 
9 Jansen E, Williams KE, Mallan KM, Nicholson JM, Daniels LA. Bidirectional associations between mothers' feeding practices and child eating behaviours. Int J Behav Nutr Phys Act. 2018 Jan;15(1):3.

10 Selzam S, McAdams TA, Coleman JR, Carnell S, O'Reilly PF, Plomin R, et al. Evidence for gene-environment correlation in child feeding: links between common genetic variation for BMI in children and parental feeding practices. PLoS Genet. 2018 Nov; 14(11):e1007757.

11 Mallan KM, Jansen E, Harris H, Llewellyn C, Fildes A, Daniels LA. Feeding a Fussy Eater: Examining Longitudinal Bidirectional Relationships Between Child Fussy Eating and Maternal Feeding Practices. J Pediatr Psychol. 2018 Nov;43(10):1138-46.

12 Mitchell GL, Farrow C, Haycraft E, Meyer C. Parental influences on children's eating behaviour and characteristics of successful parent-focussed interventions. Appetite. 2013 Jan;60(1):85-94.

13 Llewellyn $\mathrm{CH}$, van Jaarsveld $\mathrm{CH}$, Johnson L, Carnell S, Wardle J. Nature and nurture in infant appetite: analysis of the Gemini twin birth cohort. Am J Clin Nutr. 2010 May;91(5): 1172-9.

14 Fildes A, van Jaarsveld $\mathrm{CH}$, Llewellyn $\mathrm{CH}$, Fisher A, Cooke L, Wardle J. Nature and nurture in children's food preferences. Am J Clin Nutr. 2014 Apr;99(4):911-7.

15 Birch LL. Child feeding practices and the etiology of obesity. Obesity (Silver Spring). 2006 Mar;14(3):343-4

16 Wardle J, Cooke L. Genetic and environmental determinants of children's food preferences. Br J Nutr. 2008 Feb;99(S1 Suppl 1):S15-21.

17 Cooke L. The importance of exposure for healthy eating in childhood: a review. J Hum Nutr Diet. 2007 Aug;20(4):294-301.

18 Birch LL. Development of food acceptance patterns in the first years of life. Proc Nutr Soc. 1998 Nov;57(4):617-24.

19 Lange C, Visalli M, Jacob S, Chabanet C, Schlich P, Nicklaus S. Maternal feeding practices during the first year and their impact on infants' acceptance of complementary food. Food Qual Prefer. 2013;29(2):89-98.

20 Mallan KM, Fildes A, Magarey AM, Daniels LA. The Relationship between Number of Fruits, Vegetables, and Noncore Foods Tried at Age 14 Months and Food Preferences, Dietary Intake Patterns, Fussy Eating Behavior, and Weight Status at Age 3.7 Years. J Acad Nutr Diet. 2016 Apr;116(4):630-7.

21 Schwartz C, Scholtens PA, Lalanne A, Weenen $\mathrm{H}$, Nicklaus S. Development of healthy eating habits early in life. Review of recent evidence and selected guidelines. Appetite. 2011 Dec; 57(3):796-807.

22 Eneli IU, Crum PA, Tylka TL. The trust model: a different feeding paradigm for managing childhood obesity. Obesity (Silver Spring). 2008 Oct;16(10):2197-204.
23 Hurley KM, Cross MB, Hughes SO. A systematic review of responsive feeding and child obesity in high-income countries. J Nutr. 2011 Mar;141(3):495-501.

24 Wardle J, Guthrie CA, Sanderson S, Rapoport L. Development of the Children's Eating Behaviour Questionnaire. J Child Psychol Psychiatry. 2001 Oct;42(7):963-70.

25 Llewellyn $\mathrm{CH}$, van Jaarsveld CH, Johnson L, Carnell S, Wardle J. Development and factor structure of the Baby Eating Behaviour Questionnaire in the Gemini birth cohort. Appetite. 2011 Oct;57(2):388-96.

26 Llewellyn $\mathrm{CH}$, Trzaskowski M, van Jaarsveld $\mathrm{CH}$, Plomin R, Wardle J. Satiety mechanisms in genetic risk of obesity. JAMA Pediatr. 2014 Apr;168(4):338-44.

27 van Jaarsveld $\mathrm{CH}$, Boniface D, Llewellyn $\mathrm{CH}$, Wardle J. Appetite and growth: a longitudinal sibling analysis. JAMA Pediatr. 2014 Apr; 168(4):345-50.

28 Llewellyn $\mathrm{CH}$, van Jaarsveld $\mathrm{CH}$, Plomin R, Fisher A, Wardle J. Inherited behavioral susceptibility to adiposity in infancy: a multivariate genetic analysis of appetite and weight in the Gemini birth cohort. Am J Clin Nutr. 2012 Mar;95(3):633-9.

29 Webber L, Hill C, Saxton J, Van Jaarsveld CH, Wardle J. Eating behaviour and weight in children. Int J Obes. 2009 Jan;33(1):21-8.

30 Jansen PW, de Barse LM, Jaddoe VW, Verhulst FC, Franco OH, Tiemeier H. Bi-directional associations between child fussy eating and parents' pressure to eat: who influences whom? Physiol Behav. 2017 Jul;176:101-6.

31 Magarey A, Mauch C, Mallan K, Perry R, Elovaris R, Meedeniya J, et al. Child dietary and eating behavior outcomes up to 3.5 years after an early feeding intervention: the NOURISH RCT. Obesity (Silver Spring). 2016 Jul;24(7): 1537-45.

32 Chan L, Magarey AM, Daniels LA. Maternal feeding practices and feeding behaviors of Australian children aged 12-36 months. Matern Child Health J. 2011 Nov;15(8):1363-71.

33 Taylor CM, Wernimont SM, Northstone K, Emmett PM. Picky/fussy eating in children: review of definitions, assessment, prevalence and dietary intakes. Appetite. 2015 Dec;95: 349-59.

34 Dovey TM, Staples PA, Gibson EL, Halford JC. Food neophobia and 'picky/fussy' eating in children: a review. Appetite. 2008 MarMay;50(2-3):181-93.

35 Walton K, Kuczynski L, Haycraft E, Breen A, Haines J. Time to re-think picky eating?: a relational approach to understanding picky eating. Int J Behav Nutr Phys Act. 2017 May; 14(1):62.

36 Byrne R, Jansen E, Daniels L. Perceived fussy eating in Australian children at 14 months of age and subsequent use of maternal feeding practices at 2 years. Int J Behav Nutr Phys Act. 2017 Sep;14(1):123.
37 Cooke LJ, Haworth CM, Wardle J. Genetic and environmental influences on children's food neophobia. Am J Clin Nutr. 2007 Aug; 86(2):428-33.

38 Harris HA, Jansen E, Mallan KM, Daniels L, Thorpe K. Concern Explaining Nonresponsive Feeding: A Study of Mothers' and Fathers' Response to Their Child's Fussy Eating. J Nutr Educ Behav. 2018 Sep;50(8):757-64.

39 Satter E. Child of Mine. Feeding with love and good sense. Boulder, CO: Bull Publishing Co; 2000.

40 Daniels LA, Mallan KM, Battistutta D, Nicholson JM, Perry R, Magarey A. Evaluation of an intervention to promote protective infant feeding practices to prevent childhood obesity: outcomes of the NOURISH RCT at 14 months of age and 6 months post the first of two intervention modules. Int J Obes. 2012 Oct;36(10):1292-8.

41 Daniels LA, Mallan KM, Nicholson JM, Battistutta D, Magarey A. Outcomes of an early feeding practices intervention to prevent childhood obesity. Pediatrics. 2013 Jul; 132(1):e109-18.

42 Daniels LA, Mallan KM, Nicholson JM, Thorpe K, Nambiar S, Mauch CE, et al. An Early Feeding Practices Intervention for Obesity Prevention. Pediatrics. 2015 Jul;136(1):e40-9. 43 Anzman SL, Rollins BY, Birch LL. Parental influence on children's early eating environments and obesity risk: implications for prevention. Int J Obes. 2010 Jul;34(7):1116-24.

44 Birch LL, Davison KK. Family environmental factors influencing the developing behavioral controls of food intake and childhood overweight. Pediatr Clin North Am. 2001 Aug; 48(4):893-907.

45 Australian Institute of Health and Welfare. Australia's Health 2018. Canberra, Australia; 2018.

46 Reba-Harrelson L, Von Holle A, Hamer RM, Swann R, Reyes ML, Bulik CM. Patterns and prevalence of disordered eating and weight control behaviors in women ages 25-45. Eat Weight Disord. 2009 Dec;14(4):e190-8.

47 Tylka TL, Eneli IU, Kroon Van Diest AM, Lumeng JC. Which adaptive maternal eating behaviors predict child feeding practices? An examination with mothers of 2- to 5-year-old children. Eat Behav. 2013 Jan;14(1):57-63.

48 Coulthard H, Blissett J, Harris G. The relationship between parental eating problems and children's feeding behavior: a selective review of the literature. Eat Behav. 2004 May; 5(2):103-15.

49 Mallan KM, Daniels LA, Wilson JL, Jansen E Nicholson JM. Association between maternal depressive symptoms in the early post-natal period and responsiveness in feeding at child age 2 years. Matern Child Nutr. 2015 Oct; 11(4):926-35.

50 Blissett J, Meyer C, Haycraft E. Maternal mental health and child feeding problems in a non-clinical group. Eat Behav. 2007 Aug; $8(3): 311-8$. 
51 Birch LL, Fisher JO, Grimm-Thomas K, Markey CN, Sawyer R, Johnson SL. Confirmatory factor analysis of the Child Feeding Questionnaire: a measure of parental attitudes, beliefs and practices about child feeding and obesity proneness. Appetite. 2001 Jun;36(3):201-10.

52 Jansen E, Williams KE, Mallan KM, Nicholson JM, Daniels LA. The Feeding Practices and Structure Questionnaire (FPSQ-28): A parsimonious version validated for longitudinal use from 2 to 5 years. Appetite. 2016 May; 100:172-80.

53 Wardle J, Sanderson S, Guthrie CA, Rapoport L, Plomin R. Parental feeding style and the inter-generational transmission of obesity risk. Obes Res. 2002 Jun;10(6):453-62.

54 Anzman SL, Birch LL. Low inhibitory control and restrictive feeding practices predict weight outcomes. J Pediatr. 2009 Nov;155(5): 651-6.

55 Daniels LA, Mallan KM, Battistutta D, Nicholson JM, Meedeniya JE, Bayer JK, et al. Child eating behavior outcomes of an early feeding intervention to reduce risk indicators for child obesity: the NOURISH RCT. Obesity (Silver Spring). 2014 May;22(5):E104-11.
56 Frankel LA, Powell E, Jansen E. The Relationship between Structure-Related Food Parenting Practices and Children's Heightened Levels of Self-Regulation in Eating. Child Obes. 2018 Feb/Mar;14(2):81-8.

57 Fiese BH, Foley KP, Spagnola M. Routine and ritual elements in family mealtimes: contexts for child well-being and family identity. New Dir Child Adolesc Dev. 2006;2006(111):6789.

58 Byrne R, Magarey A, Daniels L. Food and beverage intake in Australian children aged 12-16 months participating in the NOURISH and SAIDI studies. Aust N Z J Public Health. 2014 Aug;38(4):326-31.

59 Daniels LA, Magarey A, Battistutta D, Nicholson JM, Farrell A, Davidson G, et al. The NOURISH randomised control trial: positive feeding practices and food preferences in early childhood - a primary prevention program for childhood obesity. BMC Public Health. 2009 Oct;9(1):387.

60 Nicklaus S, Remy E. Early origins of overeating: tracking between early food habits and later eating patterns. Curr Obes Rep. 2013; 2(2):179-84.

61 Patrick H, Nicklas TA, Hughes SO, Morales M. The benefits of authoritative feeding style: caregiver feeding styles and children's food consumption patterns. Appetite. 2005 Apr; 44(2):243-9.
62 Thebaud VC. Effect and process evaluations of an early childhood obesity prevention intervention [PhDthesis]. Brisbane: Queensland University of Technology; 2015.

63 Khandpur N, Blaine RE, Fisher JO, Davison KK. Fathers' child feeding practices: a review of the evidence. Appetite. 2014 Jul;78:110-21.

64 Hendy HM, Williams KE, Camise TS, Eckman N, Hedemann A. The Parent Mealtime Action Scale (PMAS). Development and association with children's diet and weight. Appetite. 2009 Apr;52(2):328-39.

65 Harris HA, Jansen E, Mallan KM, Daniels L, Thorpe K. Do dads make a difference? Family feeding dynamics and child fussy eating. J Dev Behav Pediatr. 2018 Jun;39(5):415-23.

66 Daniels L. Complementary feeding in an obesogenic environment: Behavioral and dietary quality outcomes and interventions. In: Black $\mathrm{RE}$, Ong KK, editors. Complementary feeding: Building the foundations for a healthy lifestyle. Nestlé Nutr Inst Workshop Ser. Volume 87. Basel: Nestec Ltd., Vevey/Karger AG; 2017. pp. 167-81.

67 Ventura AK, Birch LL. Does parenting affect children's eating and weight status? Int J Behav Nutr Phys Act. 2008 Mar;5(1):15. 